
SUSUNAN DEWAN REDAKSI

“JURNAL NASIONAL KOMPUTASI DAN TEKNOLOGI INFORMASI (JNKTI)"

\author{
Penanggung Jawab \\ Muhammad Fadhli, S.Kom, M.Kom \\ Ketua Dewan Editor \\ Zulfan, ST, MT \\ Editor Pelaksana \\ Munawir, ST, MT \\ Baihaqi, ST, MT \\ Sekretaris \\ Yeni Yanti, ST, MT \\ Mitra Bestari \\ Prof. Dr. Ir. Yuwaldi Away, M.Sc \\ Dr. Taufiq A. Gani, S.Kom, M.Eng.Sc \\ Dr. Melinda, ST, M.Sc \\ Layout \\ Eka Novendra, ST \\ Penerbit \\ Program Studi Teknik Informatika \\ Universitas Serambi Mekkah \\ Alamat Penerbit
}

Gedung H Fakultas Teknik Universitas Serambi Mekkah

Jl. T. Imum Lueng Bata, Telp. (0651)26160 Batoh - Banda Aceh 


\section{SINOPSIS}

Jurnal Nasional Komputasi dan Teknologi Informasi (JNKTI) merupakan jurnal ilmiah nasional yang diterbitkan oleh Program Studi Teknik Informatika Universitas Serambi Mekkah yang mempublikasikan artikel-artikel ilmiah dalam bidang komputasi dan teknologi informasi.Jurnal ini terbit sebanyak 2 (dua) kali dalam 1 (satu) tahun yaitu pada Bulan April dan Oktober. Bidang-bidang fokus penelitian yang akan dipublikasi dalam jurnal ini antara lain :

- Bidang Rekayasa Perangkat Lunak

- Bidang Jaringan Komputer

- Bidang Multimedia dan Pengolahan Citra Digital

- Bidang Komputasi

- Multidisiplin ilmu lainnya yang relevan 
DAFTAR ISI

JNKTI VOL.2 NO.1, APRIL 2019

Studi Simulasi Aerodinamika Airfoil dan Prediksi

$1-8$

Performa Picth Tetap Turbin Angin Poros Tegak (Darrieus)

terhadap Output Power untuk Aplikasi Kecepatan Angin Rendah

Wahyu Priyanto ${ }^{1}$, Ira Devi Sara ${ }^{2}$, Rakhmad Syafutra Lubis ${ }^{3}$

Analisis Performansi Video Streaming Dengan Menggunakan

$9-12$

Protokol RTSP Pada Jaringan IEEE 802.11n

Rahmad Rizki ${ }^{1}$, Rizal Munadi ${ }^{2}$, Syahrial $^{2}$

Pengaruh Heatsink Terhadap Kinerja Modul Surya

$13-18$

T. Mizan Sya'rani D. ${ }^{1 *}$, Ira Devi Sara ${ }^{2}$, dan Laina Hilma Sari ${ }^{3}$

Penentuan Tingkat Penyebaran Ikan Berdasarkan Citra

Suhu Permukaan Laut Di Perairan Laut Kabupaten Aceh Jaya

Menggunakan Satelit Aqua Modis

Naziran ${ }^{1}$, Rizal Munadi ${ }^{2}$, Muchlisin ${ }^{2}$

Studi Pengaruh Hibridisasi Seleksi Roullete Wheel Dengan $26-30$

Tournament Selection Menggunakan Algoritma Berevolusi Pada TSP

Cut lilis Setiawati ${ }^{1}$, Taufiq Abdul Gani ${ }^{2}$, Yuwaldi Away ${ }^{2}$

Audit Dan Optimasi Energi Listrik Pada Bangunan Kampus $31-37$

Menggunakan Metode Algoritma Genetika

Samsuddin $^{1}$, Suriadi ${ }^{2}$, Yuwaldi Away ${ }^{3}$

Aplikasi Histogram Discrete Cosine Transform (DCT) Untuk $38-42$

Sistem Temu Kembali Citra Termal Berbasis Konten

Faridah $^{1}$, Khairul Munadi ${ }^{2}$, Fitri Arnia ${ }^{3}$

Pengujian Algoritma Artificial Neural Network (ANN) $43-47$

Untuk Prediksi Kecepatan Angin

Syukri $^{1}$, Samsuddin ${ }^{2}$

Penerapan Information Retrieval Menggunakan Pemodelan $48-54$

Topik Pada Deskripsi Portal Multimedia

Indra Gita Anugrah ${ }^{1}$ dan Harunur Rosyid ${ }^{2}$

Analisa Steganografi untuk Citra Bewarna (RGB)

Menggunakan Metode Less Significant Bit (LSB)

Raihan Islamadina $^{1}$, Baihaqi $^{2}$, dan Mauzar sulistriadi ${ }^{3}$ 


\title{
Pengaruh Heatsink Terhadap Kinerja Modul Surya
}

\author{
T. Mizan Sya'rani D..$^{*}$, Ira Devi Sara ${ }^{2}$, dan Laina Hilma Sari ${ }^{3}$ \\ 1,2 Jurusan Teknik Elektro, Fakultas Teknik, Universitas syiah kuala, \\ Jalan Syekh Abdurauf As Singkili No.7, Kopelma Darussalam, Syiah Kuala, Kota Banda Aceh, Aceh 23111 \\ ${ }^{3}$ Jurusan Teknik Arsitektur, Fakultas Teknik, Universitas syiah kuala \\ Jalan Syekh Abdurauf As Singkili No.7, Kopelma Darussalam, Syiah Kuala, Kota Banda Aceh, Aceh 23111
}

Abstrak - Panas matahari yang diserap oleh modul surya dapat menaikkan suhu modul surya dan menurunkan tegangan keluarannya. Oleh karena itu perlu usaha untuk menurunkan suhu modul surya agar kinerja modul surya agar tetap optimal. Pemasangan bahan heatsink digunakan untuk mendinginkan modul surya. Pemakaian heatsink mampu menurunkan suhu modul surya sebesar $45,9^{\circ} \mathrm{C}$ lebih besar daripada tanpa menggunakan heatsink $53,3^{\circ} \mathrm{C}$ sedangkan tegangan keluaran dari modul surya mampu ditingkatkan menjadi 20,03 volt. Dari hasil penelitian dapat disimpulkan bahwa pemakaian bahan heatsink lebih baik untuk menurunkan suhu modul surya daripada tanpa menggunakan heatsink.

\section{Kata kunci : modul surya, suhu, tegangan keluaran, heatsink}

\section{Pendahuluan}

Panel fotovoltik merupakan kombinasi yang dibuat dari beberapa sel fotovoltik yang dirancang untuk mengonversikan radiasi surya ke dalam energy listrik dengan menggunakan fenomena fotovoltik. Kombinasi dari beberapa sel surya membentuk modul surya. Kombinasi dari beberapa modul surya membentuk array surya.

Pada umumnya, sel surya bisa dikategorikan menjadi 3 yakni sel surya monocrystalline (mono-Si), sel surya polycrystalline (poly-Si) dan sel surya film tipis. Efisiensi sel surya monocrystalline and polycrystalline solar bisa mencapai sebanyak $30 \%$. Sementara efisiensi sel surya film tipis bisa mencapai $20 \%$. Sisa energy lainnya terbuang dalam bentuk panas. Radiasi yang diserap oleh sel surya dapat menaikkan suhu sel surya.

Kondisi ini sangat mempengaruhi kinerja sel surya monocrystalline dan polycrystalline yang menurun drastis ketika suhu naik dimana suhu kerja normal sel surya adalah $25 \pm 1^{\circ} \mathrm{C}$, jika suhu sel surya melebihi suhu kerja normal tersebut maka tegangan keluarannya akan melemah. Untuk kenaikan suhu sel surya 1 derajat celsius saja (dari 25 derajat) dapat mengurangi $0.5 \%$ dari total tenaga yang dihasilkan [1].

Berbeda dengan tegangan, arus hubung singkat (Isc) sedikit meningkat dengan adanya kenaikan suhu. Karakteristik sistem photovoltaic (PV) yang sangat tidak linear tersebut juga dipengaruhi oleh faktor eksternal lainnya. Solar irradiation, suhu dan kecepatan angin adalah faktor lingkungan utama yang mempengaruhi PV [2][3].
Pendinginan dengan udara, pendinginan dengan cairan, imersi, pipa panas Termoelektrik dan Heatsink adalah contoh-contoh metode untuk meningkatkan efisiensi modul surya [4],[5]. Tujuan dari adalah bagaimana menurunkan suhu kerja modul surya agar mendekati kondisi normalnya yaitu suhu $25^{\circ} \mathrm{C}$ sehingga tegangan keluarannya meningkat.

\section{Studi Pustaka}

a. Modul surya

Sel surya adalah unit dasar dari sistem pembangkit energi surya di mana energi listrik diekstrak langsung dari energi cahaya tanpa proses perantara. Gabungan beberapa sel surya membentuk modul surya. Kerja sel surya hanya tergantung pada efek fotovoltaik maka sel surya juga dikenal sebagai sel fotovoltaik [5].

Sebuah sel surya pada dasarnya adalah perangkat semikonduktor. Masing-masing sel surya memiliki satu positif dan satu terminal negatif seperti semua jenis lain dari sel baterai. Sebuah semikonduktor p-n junction adalah di tengah-tengah kedua terminal tersebut. Sementara sinar matahari jatuh pada sel sehingga beberapa foton cahaya diserap oleh sel surya. Beberapa foton yang diserap akan memiliki energi lebih besar dari celah energi antara pita valensi dan pita konduksi dalam kristal semikonduktor [6].

Oleh karena itu, satu elektron valensi mendapat energi dari satu foton dan melompat keluar dari orbitalnya dan menciptakan satu pasangan elektronlubang. Elektron dan lubang pasangan e-h disebut elektron cahaya yang dihasilkan dan lubang. Elektron 
cahaya yang dihasilkan dekat p-n junction bermigrasi ke sisi n- akibat gaya elektrostatik [6].

Dengan cara ini perbedaan potensial dibentuk antara dua sisi sel dan jika kedua belah pihak yang terhubung oleh arus eksternal akan mulai mengalir dari positif ke terminal negatif dari sel surya. Ini adalah prinsip kerja dasar dari sel surya[7].

b. Heatsink (absorber)

Sebuah heat sink adalah penukar panas pasif yang memindahkan panas yang dihasilkan oleh alat elektronik atau mekanis ke medium fluida, sering berupa udara atau cairan pendingin sehingga dapat menurunkan suhu perangkat elektronik.

Di sebuah komputer, heat sink digunakan untuk mendinginkan unit pemrosesan pusat atau prosesor grafis. Heat sink digunakan pada perangkat semikonduktor berkekuatan tinggi seperti transistor daya dan Optoelektronik seperti laser dan dioda pemancar cahaya (LED), di mana Sebuah heat sink dirancang untuk memaksimalkan luas permukaan kontaknya dengan media pendingin yang mengelilinginya, seperti udara. Kecepatan udara, pemilihan perangkat, desain tonjolan dan perlakuan permukaan merupakan faktor yang mempengaruhi kinerja heat sink. Sebuah heat sink biasanya terbuat dari tembaga dan / atau aluminium.

Tembaga digunakan karena memiliki banyak sifat yang diinginkan untuk penukar panas termal yang efisien dan tahan lama. Pertama dan terutama, tembaga adalah konduktor panas yang sangat baik. Ini berarti konduktivitas termal tembaga yang tinggi memungkinkan panas melewatinya dengan cepat. Aluminium digunakan dalam aplikasi karena faktor berat aluminium yang ringan.

Sebuah heat sink mentransfer energi panas dari perangkat suhu yang lebih tinggi ke medium fluida dengan suhu yang lebih rendah. Media fluida sering udara, tapi bisa juga air, pendingin atau minyak. Jika media fluida adalah air, heat sink sering disebut cold plate.

Dalam termodinamika, heat sink adalah reservoir panas yang dapat menyerap jumlah panas tanpa perubahan suhu yang signifikan. Pemanas untuk perangkat elektronik harus memiliki suhu yang lebih tinggi daripada lingkungan untuk mentransfer panas melalui konveksi, radiasi, dan konduksi . kemampuan disipasi panas komponen itu sendiri tidak cukup untuk memoderasi suhunya [8].

\section{c. Thermoelectric Cooler (TEC)}

Pendinginan termoelektrik menggunakan efek Peltier untuk menciptakan fluks panas di antara persimpangan dua jenis material yang berbeda. Peltier pendingin, pemanas, atau pompa panas termoelektrik adalah alat yang memindahkan panas dari satu sisi perangkat ke sisi lainnya, dengan konsumsi energi listrik, tergantung pada arah arus. Instrumen semacam itu juga disebut perangkat Peltier, pompa panas Peltier, kulkas solid state, atau pendingin termoelektrik (TEC). Bisa digunakan baik untuk pemanasan maupun untuk pendinginan. Hal ini juga dapat digunakan sebagai pengendali suhu yang memanaskan atau mendinginkan [8].

Perangkat thermoelectric cooling didasarkan pada efek Peltier. Jika arus listrik melewati rangkaian dari dua konduktor yang tidak sama, maka akan terjadi kenaikan atau penurunan temperatur di persambungan tergantung dari arah aliran arus listrik. Ditemukan oleh Jean Peltier pada tahun 1834 dan kemudian diperluas oleh Emil Lenz pada tahun 1838.

Lenz menunjukkan bahwa air dapat membeku ketika diletakkan pada persambungan bismuth antimony dengan melewatkan arus listrik melalui persambungan tersebut. Lenz mengamati bahwa jika polaritas arus listrik dibalik, es dapat meleleh. Lenz menyimpulkan bahwa arah dari aliran arus listrik menentukan apakah panas diserap atau dihasilkan pada persambungan. Ketika masukan listrik diterapkan pada thermocouple, elektron bergerak dari bahan tipe $-\mathrm{p}$ ke bahan tipe $-\mathrm{n}$ menyerap energi panas pada sambungan dingin.

\section{d. Thermoelectric Generator (TEG)}

Thermoelectric Generator atau TEG adalah suatu pembangkit listrik yang didasarkan pada efek seebeck yang ditemukan oleh Thomas J. Seebeck pada tahun 1821. Ia melakukan pengamatan besar tegangan terhadap dua buah tembaga dan besi dalam sebuah rangkaian yang di antaranya diletakkan jarum kompas. Saat sisi logam dipanaskan, jarum kompas bergerak karena disebabkan oleh medan magnet yang timbul akibat aliran listrik yang terjadi pada logam.

Struktur TEG yang terdiri dari suatu susunan elemen tipe-n (material dengan kelebihan elektron) dan tipe-p (material dengan kekurangan elektron). Panas masuk pada satu sisi dan dibuang dari sisi yang lainya, menghasilkan suatu tegangan yang melewati percabangan termoelektrik. Besarnya tegangan yang dihasilkan sebanding dengan gradien suhu [9].

\section{Metode Penelitian}

Penelitian ini terdiri dari beberapa tahap sebagai berikut :

a. Persiapan perangkat dan alat penelitian.

1. Perangkat

a) Modul surya 
Modul surya yang digunakan pada penelitian ini tipe polycristalline $10 \mathrm{Wp}$ merk yunde produk china sebanyak 2 buah dan memiliki spesifikasi Panjang 36 $\mathrm{cm}$ dan Lebar 23,5 cm.

Tabel 1. Spesifikasi Modul Surya Tipe Polycristalline $10 \mathrm{wp}$

\begin{tabular}{|l|l|}
\hline Rated maximum power & $10 \mathrm{~W}$ \\
\hline Voltage at Pmax (Vmp) & $17,40 \mathrm{~V}$ \\
\hline Current at Pmax (Imp) & $0,58 \mathrm{~A}$ \\
\hline $\begin{array}{l}\text { Open - Circuit voltage } \\
\text { (Voc) }\end{array}$ & $22,04 \mathrm{~V}$ \\
\hline Short - Circuit (Isc) & $0,63 \mathrm{~A}$ \\
\hline Maximum sytem voltage & $700 \mathrm{vdc}$ \\
\hline Cell technology & Poly $-\mathrm{si}$ \\
\hline Weight & $1,2 \mathrm{~kg}$ \\
\hline Dimension & $350 * 235^{*} 18$ \\
\hline
\end{tabular}

Sebelum digunakan untuk penelitian, modul surya harus diperiksa terlebih dahulu apakah berfungsi dengan baik atau tidak. Angka dari tegangan keluaran yang diukur adalah 16.79 volt dengan suhu modul $48^{\circ} \mathrm{C}$, suhu lingkungan $37^{\circ} \mathrm{C}$.

b) Heatsink

Pemilihan Heatsink jenis ini juga dikarenakan sifat dari aluminium yang mudah atau cepat dalam melepas panas. Jumlah Heatsink yang diperlukan untuk penelitian adalah satu keping saja.

Adapun dimensi modul surya adalah sebagai berikut:

Panjang $=19,5 \mathrm{~cm}$

Lebar $=9,5 \mathrm{~cm}$

Panjang sirip $=19,5 \mathrm{~cm}$

Lebar sirip $=2,5 \mathrm{~cm}$

Tebal sirip dan tebal plat $=0,2 \mathrm{~cm}$

\section{c) Termoelektrik}

Seperti halnya Heatsink, komponen ini juga berfungsi untuk menyerap panas. Termoelektrik ini bertipe TEC 12706 yang berjumlah empat keping. Komponen ini memiliki sisi panjang yang sama dengan sisi lebarnya yaitu $4 \mathrm{~cm}$.

Adapun spsifikasi Komponen tersebut yaitu:
E-ISSN 2621-3052

Tabel 2. Spesifikasi Termoelektrik

\begin{tabular}{|l|l|}
\hline Power Supply: & $0-15.2 \mathrm{~V}$ (max.) \\
\hline The input current: & $0-6 \mathrm{~A}$ (max.) \\
\hline Power: & $60 \mathrm{~W}$ \\
\hline $\begin{array}{l}\text { Operating } \\
\text { temperature: }\end{array}$ & $-55-83^{\circ} \mathrm{C}$ \\
\hline $\begin{array}{l}\text { Dimensions: } \\
\text { one side generates heat and the cold side } \\
\text { generating }\end{array}$ \\
\hline $\begin{array}{l}\text { Modul should be used in conjunction with the } \\
\text { heatsink }\end{array}$ \\
\hline
\end{tabular}

2. Alat ukur

a) Termometer laser

Alat untuk mengukur suhu yang digunakan dalam penelitian ini berupa termometer laser merk BENETECH GM320 Non-Contact Laser dengan tujuan agar tidak ada sentuhan tangan yang dapat mempengaruhi hasil pengukuran nantinya.

b) Luxmeter digital

Alat ukur intensitas cahaya matahari yang digunakan adalah HS1010 HS1010A LCD Digital Light Meter Illuminance 1-200000LUX dalam bentuk digital dan sudah dilengkapi berbagai fitur diantaranya pemilihan tingkayt pengukuran otomatis, fungsi penahan hasil pembacaan maksimum dan minimum serta perekaman data otomatis [23].

c) Multimeter digital

Alat ukur ini digunakan untuk mengukur berbagai parameter listrik seperti arus, tegangan serta tahanan dan sudah dalam bentuk digital. Multimeter bermerk masda DT830B tersebut juga dapat menguji dioda dan transistor [24]

d) Termometer digital

Alat ini digunakan untuk mengukur suhu lingkungan di sekitar modul surya karena pengujian dilakukan di ruang terbuka. 


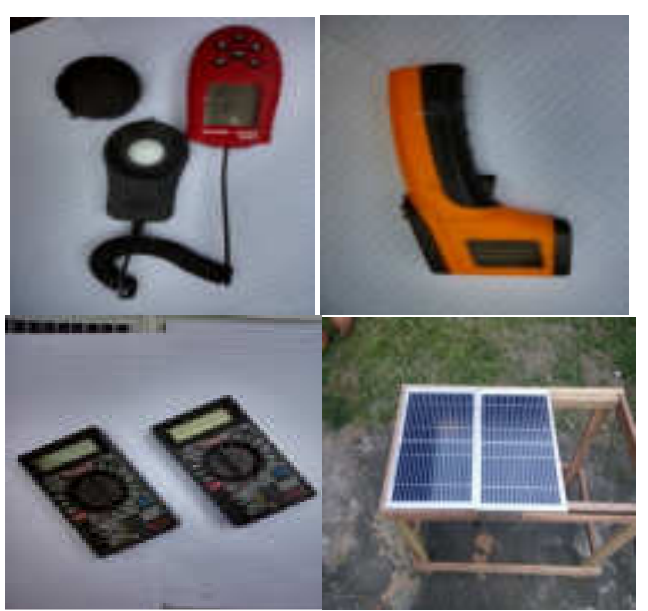

Gambar 1. Perangkat Dan Alat Ukur Yang Digunakan Pada Penelitian.

a. Pemasangan perangkat penelitian.

Sebelum dilakukan pemasangan semua perangkat yang dibutuhkan terlebih dulu dilakukan penentuan posisi penempatan modul surya yang tepat agar modul surya tidak mengalami shading sehingga modul surya akan mendapatkan efek panas dari matahari secara maksimal.

Langkah pertama yang perlu dilakukan adalah membuat tempat dudukan atau rangka penempatan modul surya. Dudukan tersebut dibuat sedemikian rupa sehingga modul surya dapat diletakkan dengan tepat serta kaki-kakinya harus sama panjang agar tidak terjadi kemiringan posisi modul suryanya.

Langkah kedua yaitu pemasangan perangkat atau komponen penyerap panas pada masing masing modul surya. Pasta termal digunakan untuk merekatkan komponen tadi dengan modul surya. Masing - masing komponen tersebut ditempelkan pada bagian bawah atau belakang dari modul surya.

Langkah ketiga memastikan kondisi alat - alat ukur yang ada apakah masih berfungsi dengan baik atau tidak dengan cara menguji satu persatu alat - alat ukur tersebut. Setelah diuji barulah penelitian siap dilaksanakan.

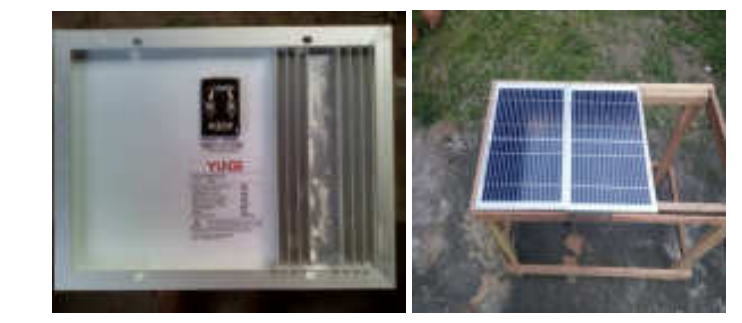

Gambar 2. Kondisi Pemasangan Perangkat Dan Modul Surya. c. Pengukuran suhu, iradiasi dan tegangan keluaran.

Setelah tahapan tersebut di atas maka langkah selanjutnya adalah mengukur berapa suhu dan tegangan keluaran modul surya.

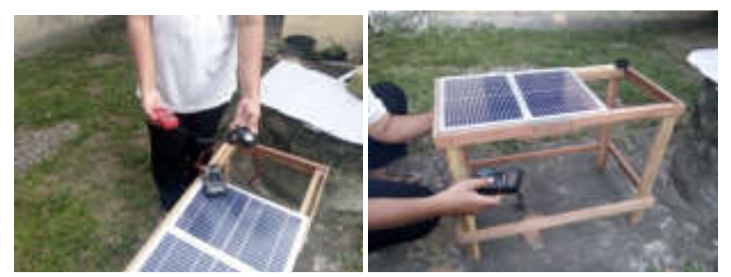

Gambar 3. Pengukuran Suhu, Iradiasi Dan Tegangan Keluaran.

Pengukuran dan pengambilan data ini dilakukan mulai dari pukul $12.00 \mathrm{~s} / \mathrm{d}$ 13.40. waktu ini dipilih karena intensitas sinar matahari sedang berada pada titik tertinggi. Rentang waktu pengukuran diambil dalam 10 menit sekali. Data yang diambil ini berupa suhu dan tegangan dimana kedua parameter tersebut menjadi indikator kinerja material yang ditempelkan pada modul surya.

b. Pengambilan data suhu modul surya dan tegangan keluaran tanpa pendingin Heatsink.

Tabel 3. Irradiasi, Suhu Lingkungan, Modul, Voc Pada Modul Tanpa Pendingin

\begin{tabular}{|c|c|c|c|c|c|}
\hline \multirow{2}{*}{\multicolumn{2}{|c|}{$\begin{array}{l}\text { Waktu } \\
\text { (menit) }\end{array}$}} & \multirow{2}{*}{$\begin{array}{l}\text { Irradia } \\
\mathrm{si} \\
\left(\mathrm{W} / \mathrm{m}^{2}\right)\end{array}$} & \multirow{2}{*}{$\begin{array}{l}\text { Suhu } \\
\text { lingkun } \\
\text { gan } \\
\left({ }^{0} \mathrm{C}\right)\end{array}$} & \multicolumn{2}{|c|}{ Tanpa pendingin } \\
\hline & & & & $\begin{array}{l}\text { Suhu } \\
\left({ }^{0} \mathrm{C}\right)\end{array}$ & $\begin{array}{l}\text { Voc } \\
\text { (Volt) }\end{array}$ \\
\hline $\begin{array}{l}12.00 \\
12.10\end{array}$ & - & 1137 & 36,0 & 53,3 & 14,42 \\
\hline $\begin{array}{l}12.10 \\
12.20\end{array}$ & - & 1129 & 33,2 & 52,0 & 14,36 \\
\hline $\begin{array}{l}12.20 \\
12.30\end{array}$ & - & 1188 & 37,2 & 54,8 & 11,24 \\
\hline $\begin{array}{l}12.30 \\
12.40 \\
\end{array}$ & - & 1173 & 37,1 & 51,2 & 14,47 \\
\hline $\begin{array}{l}12.40 \\
12.50 \\
\end{array}$ & - & 1042 & 35,7 & 50,8 & 14,59 \\
\hline $\begin{array}{l}12.50 \\
13.00 \\
\end{array}$ & - & 1037 & 34,9 & 48,3 & 15,70 \\
\hline $\begin{array}{l}13.00 \\
13.10\end{array}$ & - & 1034 & 33,6 & 45,0 & 15,40 \\
\hline $\begin{array}{l}13.10 \\
13.20\end{array}$ & - & 1028 & 32,3 & 43,6 & 15,26 \\
\hline $\begin{array}{l}13.20 \\
13.30\end{array}$ & - & 1033 & 33,8 & 41,4 & 15,00 \\
\hline $\begin{array}{l}13.30 \\
13.40 \\
\end{array}$ & - & 1031 & 33,2 & 44,5 & 15,34 \\
\hline
\end{tabular}


c. Pengambilan Data Suhu Modul Surya, Suhu Heatsink, Dan Tegangan Keluaran.
Dengan cara yang sama dengan sebelumnya, kita dapatkan data sperti terangkum dalam tabel 4.

Tabel 4. Irradiasi, Suhu Lingkungan, Modul, Voc Pada Heatsink, Dan Tegangan Keluaran.

\begin{tabular}{|c|c|c|c|c|c|}
\hline $\begin{array}{c}\text { Waktu } \\
(\text { menit })\end{array}$ & $\begin{array}{c}\text { Irradiasi } \\
\left(\mathrm{W} / \mathrm{m}^{2}\right)\end{array}$ & $\begin{array}{c}\text { Suhu } \\
\text { lingkungan } \\
\left({ }^{0} \mathrm{C}\right)\end{array}$ & $\begin{array}{c}\text { Suhu } \\
\text { Heatsink } \\
\left({ }^{\circ} \mathrm{C}\right)\end{array}$ & $\begin{array}{c}\text { Suhu modul } \\
\text { surya }\left({ }^{0} \mathrm{C}\right)\end{array}$ & $\begin{array}{c}\text { Tegangan } \\
\text { keluaran (Volt) }\end{array}$ \\
\hline $\begin{array}{c}12.00- \\
12.10\end{array}$ & 1137 & 36,0 & 43,7 & 45,9 & 20,03 \\
\hline $\begin{array}{c}12.10- \\
12.20\end{array}$ & 1129 & 33,2 & 39,9 & 40,7 & 19,45 \\
\hline $\begin{array}{c}12.20- \\
12.30\end{array}$ & 1188 & 37,2 & 42,2 & 41,5 & 19,72 \\
\hline $\begin{array}{c}12.30- \\
12.40\end{array}$ & 1173 & 37,1 & 40,7 & 43,7 & 19,55 \\
\hline $\begin{array}{c}12.40- \\
12.50\end{array}$ & 1042 & 35,7 & 39,3 & 41,4 & 19,63 \\
\hline $\begin{array}{c}12.50- \\
13.00\end{array}$ & 1037 & 34,9 & 39,6 & 41,9 & 19,37 \\
\hline $\begin{array}{c}13.00- \\
13.10\end{array}$ & 1034 & 33,6 & 35,7 & 38,7 & 19,25 \\
\hline $\begin{array}{c}13.10- \\
13.20\end{array}$ & 1028 & 32,3 & 35,8 & 39,3 & 18,89 \\
\hline $\begin{array}{c}13.20- \\
13.30\end{array}$ & 1033 & 33,8 & 36,9 & 39,0 & 19,07 \\
\hline $\begin{array}{c}13.30- \\
13.40\end{array}$ & 1031 & 33,2 & 38,8 & 40,4 & 19,27 \\
\hline
\end{tabular}

\section{Hasil Dan Pembahasan}

Dari data yang terdapat pada sejumlah tabel di atas maka langkah selanjutnya data tersebut kita bandingkan setiap parameternya ke dalam sebuah grafik sehingga kita mendapatkan gambaran bagaimana kinerja modul surya jika ditambahkan bahan penyerap panas dengan yang tidak ditambahkan apapun.

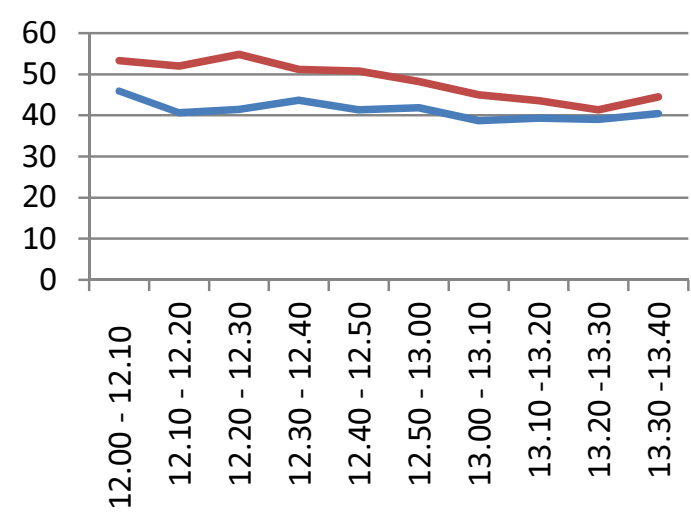

Gambar 4. Perbandingan Suhu Modul Dengan Dan Tanpa Pendingin Heatsink 


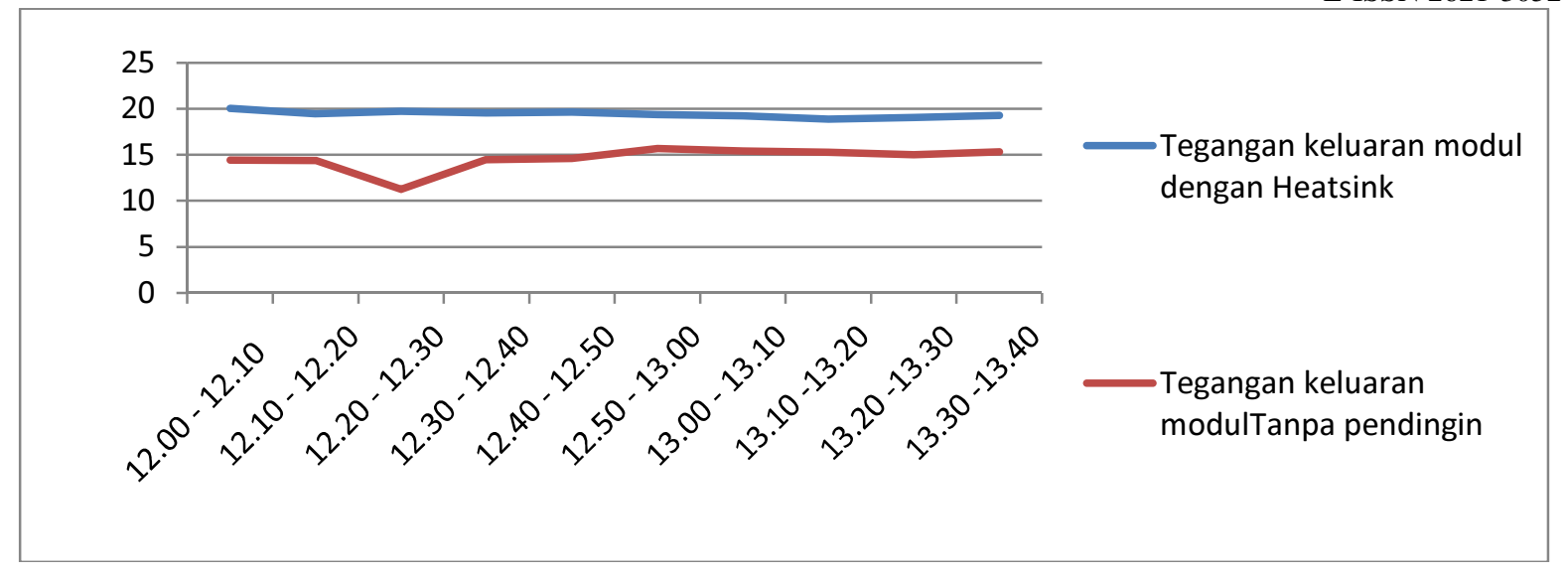

Gambar 5. Perbandingan Tegangan Keluaran Modul Surya Dengan Dan Tanpa Pendingin

Berdasarkan data yang terdapat dalam tabel dan grafik di atas menunjukkan bahwa semakin besar penurunan suhu yang terjadi maka semakin besar pula tegangan keluaran yang dihasilkan oleh modul surya. Dengan demikian dapat disimpulkan bahwa pemakaian heatsink lebih baik daripada tanpa memakai bahan penyerap panas dalam menurunkan suhu modul surya.

\section{Kesimpulan}

Untuk mempertahankan tegangan keluaran dari sebuah modul surya diperlukan adanya penambahan perangkat berbagai macam material penyerap dan pelepas panas. Penambahan Heatsink untuk menurunkan suhu modul surya ternyata lebih efektif daripada tanpa pemakaian penyerap panas. Walau demikian, diharapkan kedepannya penelitian ini dapat dilanjutkan dengan membandingkan penambahan penyerap selain heatsink.

\section{Daftar Pustaka}

[1] Haris Isyanto, Budiyanto, Fadliondi, Prian Gagani Chamdareno." Pendingin Untuk Peningkatan Daya Keluaran Panel Surya" Jurusan Teknik Elektro, Fakultas Teknik, Universitas Muhammadiyah Jakarta, Seminar Nasional Sains dan Teknologi 2017 Fakultas Teknik Universitas Muhammadiyah Jakarta , 1-2 November 2017

[2] Suriadi, Syukri Mahdi. 2010. "Perencanaan Pembangkit Listrik Tenaga Surya (PLTS) Terpadu Menggunakan Software PVSYST Pada Komplek Perumahan di Banda Aceh”. Jurnal Rekayasa Elektrika Vol. 9, No. 2.

[3] Muradi Suwargina, Imam Tri Sulistyo dan Komarudin.2015. "Studi Karakteristik Pencatuan Sel Surya Terhadap Suhu Dan Intensitas Cahaya Matahari Di Kota Cilegon", Seminar Nasional
Sains dan Teknologi 2015 Fakultas Teknik Universitas Muhammadiyah Jakarta,17 November 2015, Fakultas Teknik Elektro, STT Fatahillah, Cilegon.

[4] M. Rif'an, Sholeh HP, Mahfudz Shidiq, Rudy Yuwono, Hadi Suyono dan Fitriana S." Optimasi Pemanfaatan Energi Listrik Tenaga Matahari di Jurusan Teknik Elektro Universitas Brawijaya." Jurnal EECCIS Vol. 6, No. 1, Juni 2012.

[5] Hazlif Nazif dan Muh. Imran Hamid, "Pemodelan Dan Simulasi Pv-Inverter Terintegrasi Ke Grid Dengan Kontrol Arus "Ramp Comparison Of Current Control". Jurnal Nasional Teknik Elektro,Vol: 4, No. 2, September. 2015, ISSN: 2302 - 2949. Jurusan Teknik Elektro, Fakultas Teknik, Universitas Andalas.

[6] Kiki Kananda dan Refdinal Nazir, "Konsep Pengaturan Aliran Daya Untuk Plts Tersambung Ke Sistem Grid Pada Rumah Tinggal”, Jurnal Nasional Teknik Elektro, Vol: 2 No.2 September 2013, ISSN: 2302-2949, Jurusan Teknik Elektro, Fakultas Teknik, Universitas Andalas.

[7] Sartono Putro,"Pengujian Pembangkit Listrik Tenaga Surya Dengan Posisi Pelat Photovoltaic Horizontal". Jurusan Teknik Mesin Fakultas Teknik Universitas Muhammadiyah Surakarta.

[8] Baharuddin, Agli Hariyanto, 2015," Konversi Energi Panas Penggerak Utama Kapal Berbasis Thermoelectric." Jurnal Riset Dan Teknologi Kelautan (Jrtk) Volume 13, Nomor 1.

[9] Tinton Dwi Atmaja, Ghalya Pikra dan Kristian Ismail," Manajemen Termal Heat Sink pada Modul Kendali Motor Kendaraan Hibrid”, Pusat Penelitian Tenaga Listrik dan Mekatronik LIPI, Bandung. 
